\title{
Monitoring physiological responses and fluid balance of elite female beach handball players during an international tournament
}

\author{
Bayram Ceylan $^{\mathrm{ABCDE}}$, Kerem M. ${ }^{\mathrm{ABCDE}}$, Ceyiz S. ${ }^{\mathrm{ABCDE}}$, Gurses V.V. ${ }^{\mathrm{ABCDE}}$, Akgül M.Ş. ${ }^{\mathrm{ABCDE}}$, Baydil B. ${ }^{\mathrm{ABCDE}}$ \\ Kastamonu University, Kastamonu, Turkey \\ Authors' Contribution: A - Study design; B - Data collection; C - Statistical analysis; D - Manuscript Preparation; \\ E - Funds Collection.
}

\begin{abstract}
Purpose: $\quad$ Despite its increasing popularity, beach handball has not been studied in terms of physiological responses. Thus the aim of this study was to demonstrate lactate and heart rate responses as well as urine specific gravity (USG) levels and fluid intakes of female university students who competed at an international beach handball tournament.

Material: $\quad$ Five university students who are also handball players (age: $21 \pm 1,2$, body weight: $56,6 \pm 6,4$, height:1,61 $\pm 0,06$ and BMI: $21,7 \pm 1,43)$ voluntarily participated in this study. Heart rate $(H R)$, lactate level $(L A)$ and USG were measured before each and immediately after each competition and fluid intake during competition was monitored.

Results: $\quad$ The mean values of lactate accumulation and heart rate before and after the match were $1,4 \mathrm{mmol}$ and $87,3,5,0$ and 123,9 , respectively. Athletes were euhydrated before the matches $\left(\mathrm{USG}_{\text {mean }}=1,018\right)$ and only presented dehydration after the second match.

Conclusions: Beach handball does not result in strenuous physiological effects according to heart rate and lactate responses. Their fluid intake was not enough to eliminate dehydration. Despite fluid availability during the match they presented dehydration at the second match.

Keywords: student, beach handball, lactate, heart rate, match performance.
\end{abstract}

\section{Introduction}

Beach handball is a challenging sport where two teams pass a ball in order to score a goal. It is characterized by fast-paced and end-to-end actions. Beach handball is a relatively new type of sport derived from team handball [1], recognized by several international federations [2]. Today, there are professional and amateur beach handball leagues in many countries in Europe, and beach handball has been included in the 2018 Youth Olympic Games program. [3]. Beach handball is played in a $15 \times 12 \mathrm{~m}$ sandy area with teams consisting of 1 goalkeeper and 3 field players in two halves of $10(2 \times 10)$ minutes [2].

To improve performance in sports, a special training consisting of physical and physiological analysis provides scientists and coaches with accurate information about routines and goals [4]. As an indicator of physiological burden, the evaluation of athletes together with heart rate (HR) measurements is crucial to determine whether there is a difference between competitiveness levels [4]. Furthermore, heart rate can be a useful indicator of circulatory tension apart from being a carrier for energy expenditure [5].

Fluid balance has been reported to be very important in terms of performance and health [6]. Maintaining fluid homeostasis is of great importance for athletic performance and thermoregulation in humans. Previous studies [7, 8] highlighted that even moderate level of dehydration impairs athletic performance by increasing physiological strain as well as resulting in fluctuations in heart rate and reduction in cardiac output which results (c) Bayram Ceylan, Kerem M., Ceyiz S., Gurses V.V.,

Akgül M.Ş., Baydil B., 2020

doi:10.15561/20755279.2020.0203 in inability to dissipate heat. Especially in hot and humid environment athletes are exposed to high sweating rates which adversely affects performance if athletes are not acclimatized to the environment. As beach handball players compete under hot environment it is of great importance to monitor fluid balance during training and competition.

To our knowledge there has been no study investigating physiological responses and fluid balance of university level beach handball players during a tournament. It was hypothesized that each match would result in high lactate accumulation and heart rate response and female university students would present high level of dehydration. Thus, this study aimed to demonstrate lactate and heart rate responses as well as urine specific gravity (USG) levels and fluid intakes of female university students who competed at an international beach handball tournament.

\section{Materials and methods}

Participants: Five university students who are also handball players (age: $21 \pm 1,2$, body weight: $56,6 \pm 6,4$, height:1,61 $\pm 0,06$ and BMI: 21,7 $\pm 1,43$ ) voluntarily participated in this study. Eligibility criteria were at least 5-year handball experience, not having any injury which affects their performance. Participants were informed about the nature of the study and signed the informed consent form before the measurements. The study was carried out in accordance with the latest version of Declaration of Helsinki.

Research design: The nature of this study is descriptive. The study was carried out during an international 
tournament. Measurements were implemented as follows: determining heart rate (HR), lactate level (LA) and USG before each and immediately after each competition and monitoring fluid intake during competition.

Heart rate measurement: HR measurement was carried out with SEEGO RealTrack (Spain) heart rate monitor.

Lactate measurement: Lactate levels of the participants were determined with Lactate Plus (USA) from the participants' fingertips by collecting almost $25 \mu$ l of blood and placing the blood directly on the strip. Before the measurement, fingertips of the participants were cleaned with cotton soaked in alcohol and dried well.

Hydration measurements: Urine samples were collected from all the participants in a sterilized plastic container before and immediately after each match. Immediately after determining USG values with a digital refractometer (ATAGO PAL-10S, Japan) all urine samples were discarded. Hydration status of the participants were classified according to the suggestion of National Athletic Trainers' Association Position Statement [9] ( $\leq 1.020 \mathrm{~g} /$ $\mathrm{mL}$ euhydrated, $\geq 1.020 \mathrm{~g} / \mathrm{mL}$ dehydrated).

Statistics: Data were given as mean and standard deviations. Descriptive statistic was implemented for demographic, physiological variables, USG values and fluid intake. Repeated measures were used to determine the difference in variables among different times. Spearman correlation test was used to verify the relationship between fluid intake and changes in hydration status before and after the matches. Correlations were classified according to Hopkins [10]. SPSS 20 was used for statistical analysis and $\mathrm{p}$ value was set as $\mathrm{p}<0,05$.

\section{Results}

Table 1 presents lactate and heart rate responses as well as USG values and fluid intake of female university students before and after three matches.

When the correlations between fluid intake and hydration changes were evaluated, moderate negative correlation was found between fluid intake and hydration change at the first match $(\mathrm{r}=-0,28, \mathrm{p}>0,05)$, very large negative correlation was found between fluid intake and hydration change at the second match $(\mathrm{r}=-0,64, \mathrm{p}>0,05)$ and nearly perfect negative correlation was found between fluid intake and hydration change at the third match $(\mathrm{r}=$ $0,80, \mathrm{p}>0,05)$.

Figure 1 presents the changes in lactate accumulations

Table 1. Lactate, hearth rate, USG values and fluid intake of female handball players.

\begin{tabular}{|c|c|c|c|c|}
\hline Variables $(n=5)$ & Minimum & Maximum & Mean & SD \\
\hline \multicolumn{5}{|l|}{ First Match } \\
\hline $\mathrm{LA}_{\text {rest }}(\mathrm{mmol} / \mathrm{L})$ & 0,9 & 1,4 & 1,1 & 0,1 \\
\hline $\mathrm{LA}_{\text {post }}(\mathrm{mmol} / \mathrm{L})$ & 3,5 & 9,3 & 6,2 & 2,8 \\
\hline $\mathrm{HR}_{\text {rest }}(\mathrm{bpm})$ & 72 & 100 & 85,4 & 12,7 \\
\hline $\mathrm{HR}_{\text {post }}(\mathrm{bpm})$ & 111 & 136 & 125,6 & 10,6 \\
\hline $\mathrm{USG}_{p r e}(\mathrm{~g} / \mathrm{mL})$ & 1,018 & 1,020 & 1,018 & 0,000 \\
\hline USG $_{\text {post }}(\mathrm{g} / \mathrm{mL})$ & 1,013 & 1,023 & 1,018 & 0,044 \\
\hline Fluid intake (L) & 0,5 & 0,8 & 0,6 & 0,1 \\
\hline \multicolumn{5}{|l|}{ Second Match } \\
\hline $\mathrm{LA}_{\text {rest }}(\mathrm{mmol} / \mathrm{L})$ & 1,2 & 1,9 & 1,6 & 0,2 \\
\hline $\mathrm{LA}_{\text {post }}(\mathrm{mmol} / \mathrm{L})$ & 2,3 & 6,9 & 4,3 & 1,9 \\
\hline $\mathrm{HR}_{\text {rest }}(\mathrm{bpm})$ & 71 & 102 & 87 & 11,7 \\
\hline $\mathrm{HR}_{\text {post }}(\mathrm{bpm})$ & 107 & 150 & 123,2 & 17,2 \\
\hline $\mathrm{USG}_{\text {pre }}(\mathrm{g} / \mathrm{mL})$ & 1,012 & 1,022 & 1,015 & 0,004 \\
\hline USG $_{\text {post }}(\mathrm{g} / \mathrm{mL})$ & 1,016 & 1,028 & 1,021 & 0,004 \\
\hline Fluid intake (L) & 0,8 & 1 & 0,85 & 0,13 \\
\hline \multicolumn{5}{|l|}{ Third Match } \\
\hline $\mathrm{LA}_{\text {rest }}(\mathrm{mmol} / \mathrm{L})$ & 1,4 & 1,8 & 1,5 & 0,1 \\
\hline $\mathrm{LA}_{\text {post }}(\mathrm{mmol} / \mathrm{L})$ & 2,8 & 7,2 & 4,5 & 1,8 \\
\hline $\mathrm{HR}_{\text {rest }}(\mathrm{bpm})$ & 80 & 101 & 89,6 & 8,7 \\
\hline $\mathrm{HR}_{\text {post }}(\mathrm{bpm})$ & 118 & 128 & 123 & 4 \\
\hline $\mathrm{USG}_{\text {pre }}(\mathrm{g} / \mathrm{mL})$ & 1,006 & 1,015 & 1,020 & 0,003 \\
\hline $\mathrm{USG}_{\text {post }}(\mathrm{g} / \mathrm{mL})$ & 1,008 & 1,028 & 1,014 & 0,008 \\
\hline Fluid intake (L) & 0,5 & 1 & 0,75 & 0,17 \\
\hline
\end{tabular}

$\mathrm{LA}=$ Lactate accumulation, $\mathrm{HR}=$ Heart rate, USG=Urine specific gravity 


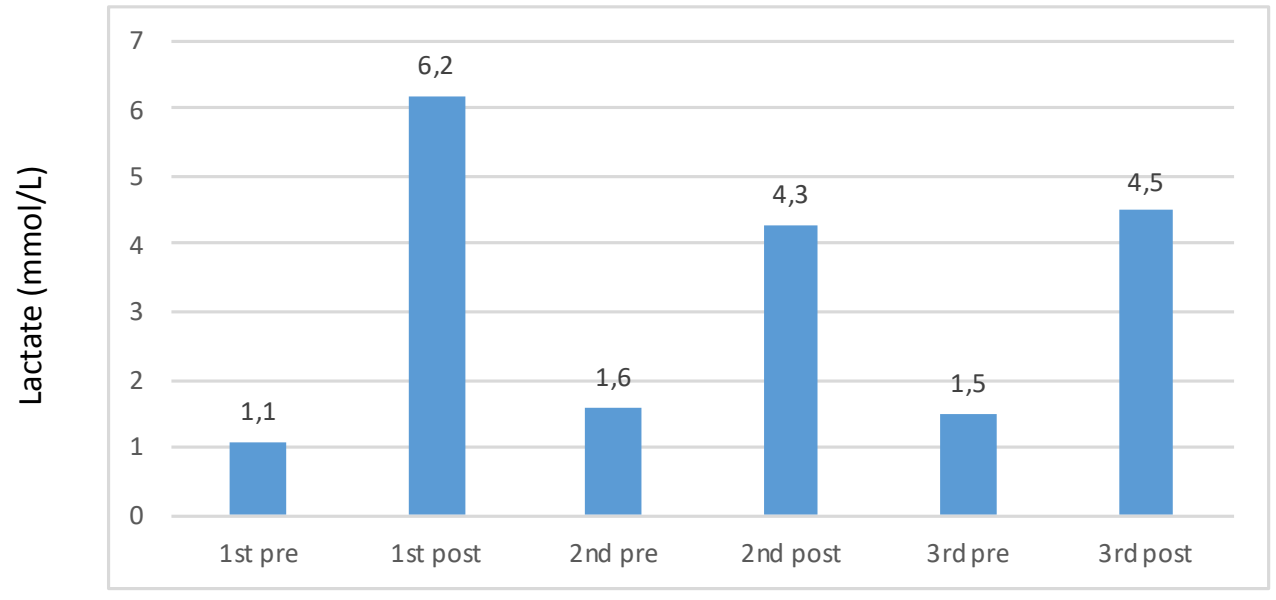

matches

Figure 1. Lactate responses of female university students before and after beach handball matches

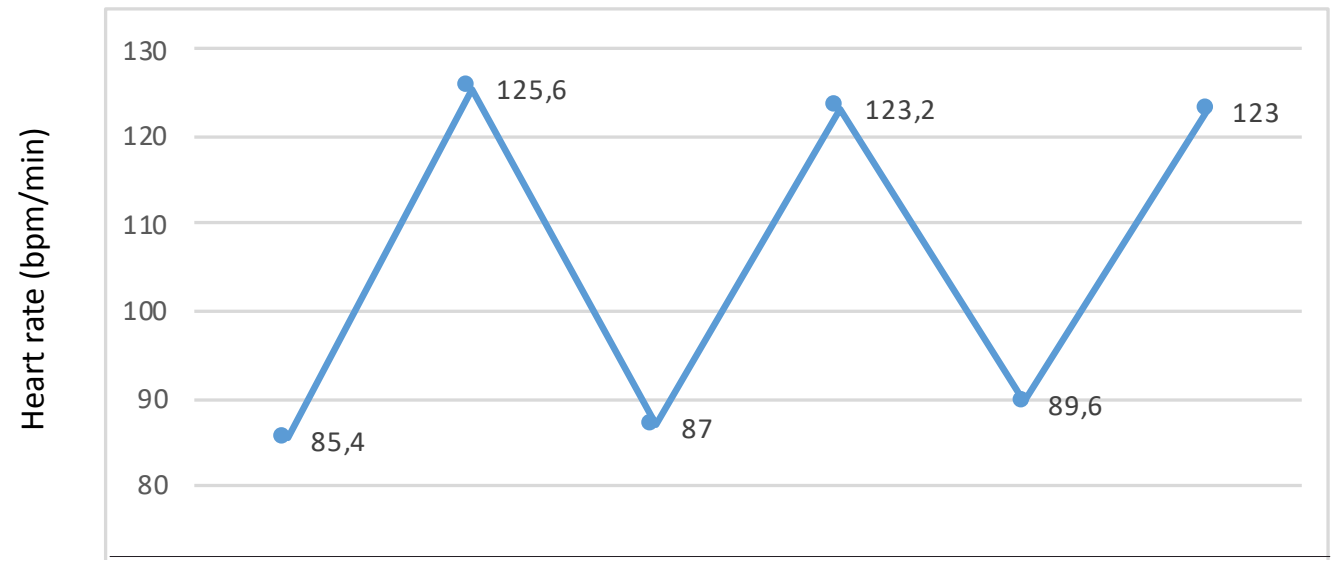

matches

Figure 2. Heart rate responses of female university students before and after each beach handball match

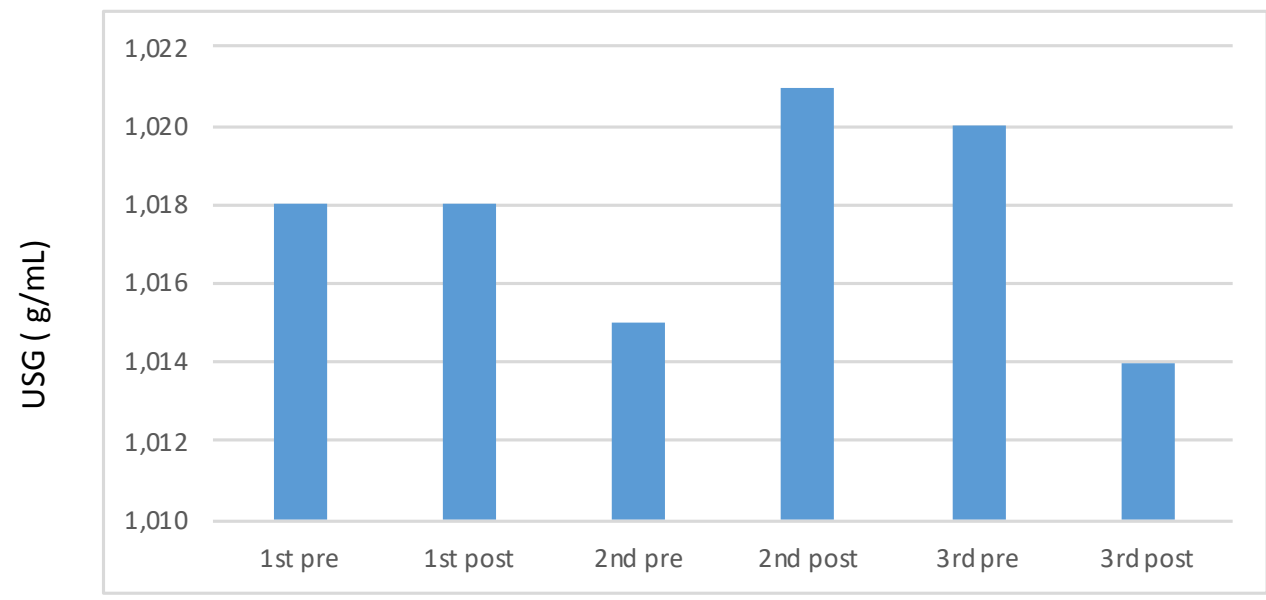

matches

Figure 3. Changes in USG values of female university students before and after beach handball matches 
during three different matches of the beach handball players. Resting values of lactate levels were found similar between measurements $(F=6,12 ; p=0,052)$. Similarly, no difference was found in post-match lactate levels between measurements $(\mathrm{F}=1,32 ; \mathrm{p}=0,314)$.

Heart rate responses of female university students before and after beach handball match are presented in Figure 1. Resting heart rate values were compared and no difference was found $(\mathrm{F}=2,18 ; \mathrm{p}=0,182)$ and postmatch heart rate values were also found similar $(\mathrm{F}=0,75$; $\mathrm{p}=0,901)$.

Changes in hydration levels of the participants can be found in Figure 3. As for USG values before and after the matches, difference was found pre-match $(\mathrm{F}=4,98$; $\mathrm{p}=0,049$ ) while no difference was found in post-match values $(F=2,07 ; p=0.212)$.

\section{Discussion}

The purpose of the present study was to demonstrate physiological responses and hydration status as well as fluid intakes of female university students who competed at an international beach handball tournament. The main findings of the study were:

1) all the athletes started competition with low level of lactate level,

2) athletes completed the matches with a mean value of lactate level of $6 \mathrm{mmol} / \mathrm{L}$.

3) Post-match heart rate responses varied from 107 to 150.4$)$ Athletes were mostly hydrated and maintained this during the matches.

Determining the intensity of a physical activity is fundamental to determine training goals and its planning later on. Therefore, it is of great importance to evaluate physiological outputs during a real competition environment. Heart rate has been used for determining the energy level that an activity needs. Although there have been studies monitoring heart rate responses of indoor handball players [11, 12, 13], there is obviously lack of studies in terms of monitoring heart rate responses following a beach handball match. To our knowledge, the only study investigating heart rates of handball players belongs to Lara Cobos [2] which monitored heart rate values during matches. The author stated a mean heart rate of $176 \mathrm{bpm}$ during the first half of the match while it was $172 \mathrm{bpm}$ during the second half. Another study examined heart rates of indoor football players and stated the mean heart rate as $172 \mathrm{bpm}$ [14] while another study implemented on female basketball players indicated a mean heart rate of $170 \pm 8 \mathrm{bpm}$ [15]. In contrast to abovementioned studies, heart rate responses measured immediately after the match was very low.

Lactate is the only metabolic parameter indicating the skill of muscles for a specific athletic performance. The skill of muscles means the ability of muscles to achieve maximum performance during a sports activity for maintaining harmonious and balanced energy required by the activity. Monitoring lactate accumulation helps coaches to determine the intensity of exercises and plan the training program. To the best of our knowledge, the only study investigating lactate accumulation during an official beach handball match presented that lactate accumulation was found as $13.8 \mathrm{mmol} / \mathrm{L}$ and $14.1 \mathrm{mmol} / \mathrm{L}$ in the middle and at the end of the first set, respectively, and $11.7 \mathrm{mmol} / \mathrm{L}$ and $12.0 \mathrm{mmol} / \mathrm{L}$ in the middle and end of the second set, respectively [16]. A study by Kaya et al. [17] investigated lactate responses in indoor sports athletes during various loads and stated that lactate accumulation increases with the increasing load. Our findings are significantly lower than those found by Silva et al. That may stem from the aerobic, anaerobic capacities of the athletes or intensity of the matches.

Maintaining fluid balance of the body is very important for athletes especially for those who compete under humid and hot conditions. Karras et al. [18] monitored fluid loss of handball players by monitoring body weight changes during official matches in high humidity and temperature and stated that athletes presented dehydration despite consuming 1 liter of water during the game. In our study, athletes started first and second matches euhydrated although they presented dehydration before the third match. When post-match values are evaluated, athletes were euhydrated after first and third matches although they presented significant dehydration after the second match. Despite higher fluid intake during the second match they presented higher dehydration compared to first and third matches. Findings of Karras et al [18] supports our findings as athletes presented dehydration despite consuming fluid during the match.

\section{Conclusion}

In conclusion, beach handball does not result in strenuous physiological effects according to heart rate and lactate responses. Athletes' fluid intake was not enough to eliminate dehydration. Despite fluid availability during the match they presented dehydration at the second match. It can be suggested that physiological responses and hydration status during training and field tests are monitored and athletes should be informed about the adverse effects of dehydration and encouraged to consume enough water especially when they compete under humid and hot conditions and also coaches should be informed and as they are the most influential people on athletes they should pay attention to the fluid consumption, physiological responses to training and match should develop themselves [19].

\section{Acknowledgment}

Authors presents their greetings to Kastamonu University Female Handball Team for their participation in this study. This study was not funded by any organization.

\section{Conflict of interests}

The authors declare that there is no conflict of interests. 


\section{References}

1. Achenbach L, Loose O, Laver L, Zeman F, Nerlich $\mathrm{M}$, Angele $\mathrm{P}$, et al. Beach handball is safer than indoor team handball: injury rates during the 2017 European Beach Handball Championships. Knee Surg Sports Traumatol Arthrosc, 2018;26:1909-1915. https://doi.org/10.1007/s00167-018-4907-5

2. Lara Cobos D. Analysis of heart rate in female beach handball players. Apunts Medicina de l'Esport, 2011;46:131-136. https://doi.org/10.1016/j.apunts.2011.02.001

3. Hatzimanouil D, Papasoulis E, Terzidis I, Kanioglou A, Mavropoulou A, Natsis K. Injuries in elite athletes of beach handball. Journal of Human Sport and Exercise, 2017; 12(3): 689-697. https://doi.org/10.14198/jhse.2017.123.13

4. Pueo B, Jimenez-Olmedo JM, Penichet-Tomas A, Becerra MO, Agullo, JJE. Analysis of time-motion and heart rate in elite male and female beach handball. Journal of sports science medicine, 2017;16(4): 450.

5. Drust B, Atkinson G, Reilly T. Future perspectives in the evaluation of the physiological demands of soccer. Sports medicine, 2007;37(9): 783-805.

6. Gurses VV, Ceylan B, Sakir M, Baydil B, Al Hussein $\mathrm{H}$, Badau D. Dehydration and Acute Weight Gain of Athletes Before Sport Competitions. Revista De Chimie, 2018;69(11):4096-4098.

7. Gonzalez-Alonso J, Mora-Rodriguez R, Below PR, Coyle EF. Dehydration reduces cardiac output and increases systemic and cutaneous vascular resistance during exercise. Journal of Applied Physiology, 1995; 79(5): 1487-1496. https://doi.org/10.1152/jappl.1995.79.5.1487

8. José G-A, Mora-Rodríguez R, Below PR, Coyle EF. Dehydration markedly impairs cardiovascular function in hyperthermic endurance athletes during exercise. Journal of Applied Physiology, 1997;82:1229-36. https://doi.org/10.1152/jappl.1997.82.4.1229

9. Sawka MN, Burke LM, Eichner ER, Maughan RJ, Montain SJ, Stachenfeld NS. American College of Sports Medicine position stand. Exercise and fluid replacement. Medicine and science in sports and exercise, 2007; 39(2): 377-390. https://doi.org/10.1249/mss.0b013e31802ca597
10.Hopkins WG. A Scale of Magnitudes for Effect Statistics. [Internet]. 2002. [updated 2019; cited 2017 Nov 03]. Available from: https://www.sportsci.org/resource/stats/ effectmag.html

11.Alexander MJ, Boreskie SL. An analysis of fitness and time-motion characteristics of handball. The American journal of sports medicine, 1989;17(1):76-82. https://doi.org/10.1177/036354658901700113

12.Loftin M, Anderson P, Lytton L, Pittman P, Warren B. Heart rate response during handball singles match-play and selected physical fitness components of experienced male handball players. The Journal of sports medicine and physical fitness, 1996;36(2): 95-99.

13. Gintaré Onusaitytè AS. High-skill handcuffs were introduced by the change in work intensity during the match. Ugdymas. Küno Kultüra.Sportas, 2009, 2(73): 15-22. (In Lithuanian)

14.Barbero-Alvarez J, Soto VM, Barbero-Alvarez V, GrandaVera J. Match analysis and heart rate of futsal players during competition. Journal of sports sciences, 2008;26(1):63-73. https://doi.org/10.1080/02640410701287289

15.MatthewD, DelextratA.Heartrate, bloodlactate concentration, and time-motion analysis of female basketball players during competition. Journal of sports sciences, 2009;27(8): 813-821. https://doi.org/10.1080/02640410902926420

16.Silva AS, Coeli RSM, DE SAL, Guedes DS, Lacerda LM, Silva DC, Soares YM. Physiological and nutritional profile of elite female beach handball players from Brazil. The Journal of sports medicine and physical fitness, 2016;56(5):503-509. https://europepmc.org/abstract/med/25665744

17.Kaya I, Kalkavan A, Senturk A, Harmancil H, Karavelioglu M, Yuksel O, Savasli M. Analysis of blood lactate and heart rate of indoor sports athletes as a response to various loads. Turkish Journal of Sport and Exercise, 2013;15(3): 86-89.

18.Karras D, Chryssanthopoulous C, Diafas V. Body fluid loss during four consecutive beach handball matches in high humidity and environmental temperatures. Serbian Journal of Sport Sciences, 2007;1(1): 8-13.

19. Yaşar OM, Sunay, H. Investigation of job satisfaction and organizational commitment level of football coaches. Journal of Human Sciences, 2018, 15(2), 952- 969. https://doi.org/10.14687/jhs.v15i2.5239 


\section{Information about the authors:}

Bayram Ceylan; (Corresponding author); http://orcid.org/0000-0002-6753-1848; bceylan@kastamonu.edu.tr; School of Physical Education and Sport, Kastamonu University; Kastamonu, Turkey.

Kerem M.K.; http://orcid.org/0000-0001-8497-9460; mkerem@kastamonu.edu.tr; School of Physical Education and Sport, Kastamonu University; Kastamonu, Turkey.

Çeyiz S.Ç; http://orcid.org/0000-0002-1000-0309; sceyiz@kastamonu.edu.tr; School of Physical Education and Sport, Kastamonu University; Kastamonu, Turkey.

Gürses V.V.G.; http://orcid.org/0000-0002-6249-3504; vgurses@kastamonu.edu.tr; School of Physical Education and Sport, Kastamonu University; Kastamonu, Turkey.

Akgül M.Ş.A.; http://orcid.org/0000-0002-9696-6541; msakgul@kastamonu.edu.tr; School of Physical Education and Sport, Kastamonu University; Kastamonu, Turkey.

Baydil B.B.; http://orcid.org/0000-0002-9161-2381; bilgehan@kastamonu.edu.tr; School of Physical Education and Sport, Kastamonu University; Kastamonu, Turkey.

Cite this article as:

Bayram Ceylan, Kerem M, Ceyiz S, Gurses VV, Akgül MŞ, Baydil B. Monitoring physiological responses and fluid balance of elite female beach handball players during an international tournament. Physical education of students, 2020;24(2):86-91. https://doi.org/10.15561/20755279.2020.0203

This is an Open Access article distributed under the terms of the Creative Commons Attribution License, which permits unrestricted use, distribution, and reproduction in any medium, provided the original work is properly cited http://creativecommons.org/licenses/by/4.0/deed.en

Received: 22.02 .2020

Accepted: 29.03.2020; Published: 30.04 .2020 